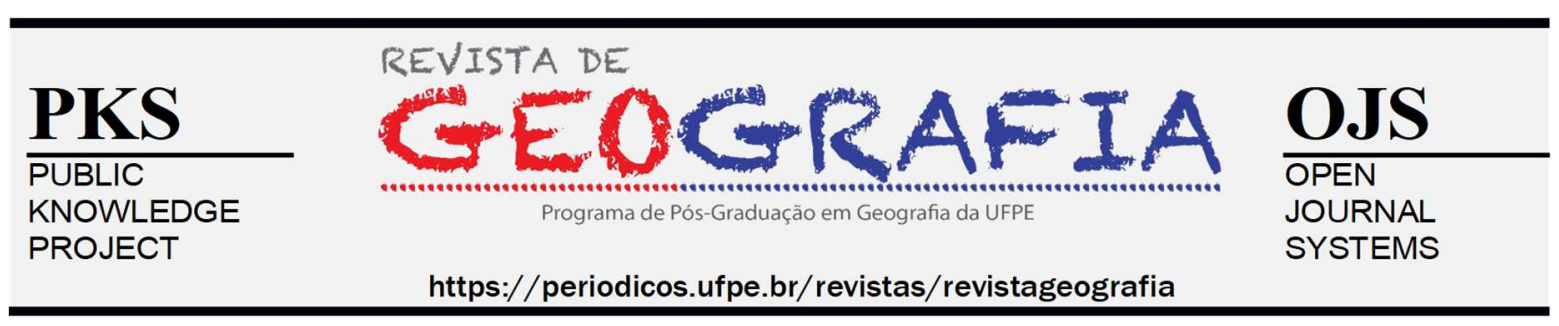

\title{
A TERRITORIALIZAÇÃO DA EXPLORAÇÃO DO TRABALHO NO TERRITÓRIO DE IDENTIDADE DO SISAL - BAHIA
}

\author{
Luis Eduardo Cunha Silva ${ }^{1}$, Ana Rocha dos Santos ${ }^{2}$ \\ 1 Universidade Federal de Sergipe/Programa de Pós Graduação de Geografia. E-mail: \\ edugeo.cunha@gmail.com \\ 2 Universidade Federal de Sergipe/Programa de Pós Graduação de Geografia. E-mail: \\ ana.rochaufs@gmail.com
}

Artigo recebido em 07/10/2019 e aceito em 03/06/2020

\begin{abstract}
Resumo: A análise realizada no presente texto está centrada no estudo da exploração do trabalho no Território de Identidade do Sisal, localizado na porção centro norte do estado da Bahia. Este território de identidade tem como forte característica a unidade da cultura do sisal que se desenvolve por meio de um processo constante de exploração do trabalho nos campos de cultivo da fibra, expondo os trabalhadores às condições precárias, cenário de miserabilidade social que não condiz com a valiosa importância do produto no mercado internacional. A expansão da produção da fibra de sisal no cenário baiano para atender a cadeia de exportação está sempre acompanhada do aprofundamento da exploração do trabalho nos campos de produção, condição que potencializa a motivação em compreender a dinâmica de produção da fibra como fator condicionante da (re)produção espacial. Como procedimentos metodológicos usou-se pesquisa bibliográfica e trabalho de campo em determinadas localidades. Nessa perspectiva tornou-se a Geografia uma ciência imprescindível na função de interpretação das contradições deste processo. Destarte identificou-se uma profunda subordinação da mão de obra aos ditames do mercado de exportação, expondo com isso a permanente contradição entre as relações de produção e mercado da fibra para a exportação.
\end{abstract}

Palavras-chave: Território; Subordinação; Trabalho; Desenvolvimento; Internacional.

\section{TERRITORIALIZATION OF LABOR EXPLOITATION IN THE SISAL IDENTITY TERRITORY - BAHIA}

\begin{abstract}
The analysis carried out in this text is centered on the study of labor exploitation in the Sisal Identity Territory, located in the north central portion of the State of Bahia. This territory of identity has as its strong characteristic the unity of sisal culture that develops through a constant process of exploitation of the work in the fields of fiber cultivation, exposing the workers to the precarious conditions, scenario of social miserability that does not match the valuable importance of the product in the international market. The expansion of sisal fiber production in the Bahian scenario to serve the export chain is always accompanied by the deepening of labor exploration in the production fields, a condition that enhances the motivation to understand the fiber production dynamics as a conditioning factor for space (re) production. As methodological procedures it was used bibliographic research and field work in certain locations. From this perspective, geography has become an indispensable science in the function of interpreting the contradictions of this process, thus identifying a deep subordination of labor to the dictates of the export market, thus exposing a permanent contradiction between the relations of production and market of fiber for export.
\end{abstract}

Key-words: Subordination; Labor; Development; International. 


\section{INTRODUÇÃO}

O Território de Identidade do Sisal (Mapa 1) reúne vinte municípios do estado da Bahia, sendo estes inseridos no semiárido baiano, em um polígono de estiagem prolongada e permanentes problemas sociais vinculados aos conflitos fundiários e precarização das condições de vida dos trabalhadores no campo. As nuances de organização do trabalho no Território do Sisal não se distinguem muito dos demais cenários nordestinos de precariedade da vida humana e permanente exploração de mão de obra. Atrelado a isso, o cenário de miserabilidade social, associado aos períodos de estiagem pluviométrica, serve até os dias atuais como justificativa para que o Estado gerencie políticas de combate à seca que por décadas operam em função dos interesses de determinadas lideranças políticas, como um atrativo de recursos externos de cunho financeiro que acabam por contribuir para a manutenção das oligarquias agrárias no poder. Além disso, reproduz um ideário de que toda a responsabilidade do cenário de pobreza no Nordeste brasileiro é causada exclusivamente pelas estiagens prolongadas, narrativa que torna secundária a responsabilização das oligarquias políticas na manutenção da pobreza e constante precarização do trabalho.

As condições adversas que a natureza impõe são vinculadas à retórica da classe dominante (devidamente representada no Estado) para afirmar que as dificuldades da população sertaneja provinham e ainda provêm, exclusivamente, das condições climáticas naturais. O imaginário da seca nordestina como tragédia social e econômica faz da natureza um ente quase metafísico, idealizada e trabalhada nos discursos, como obstáculo ao progresso e à justiça social (SANTOS, 2008, p.127).

No entanto, o que presenciamos na atualidade é um cenário territorial dual, marcado por contradições entre precárias relações de trabalho e a concentração da renda. Além disso, cabe ressaltar que a institucionalização dos programas de desenvolvimento territorial que, estabelece o Território de Identidade do Sisal no estado da Bahia, é um importante elemento nesse debate, tendo em vista que mesmo diante das suas ações de incentivo às cadeias produtivas presentes no território, as relações de exploração do trabalho nos campos de plantio e desfibramento do sisal permanecem marcadas pela precarização da mão de obra. 


\section{Mapa 1: Bahia, Localização do Território de Identidade do Sisal, 2018.}
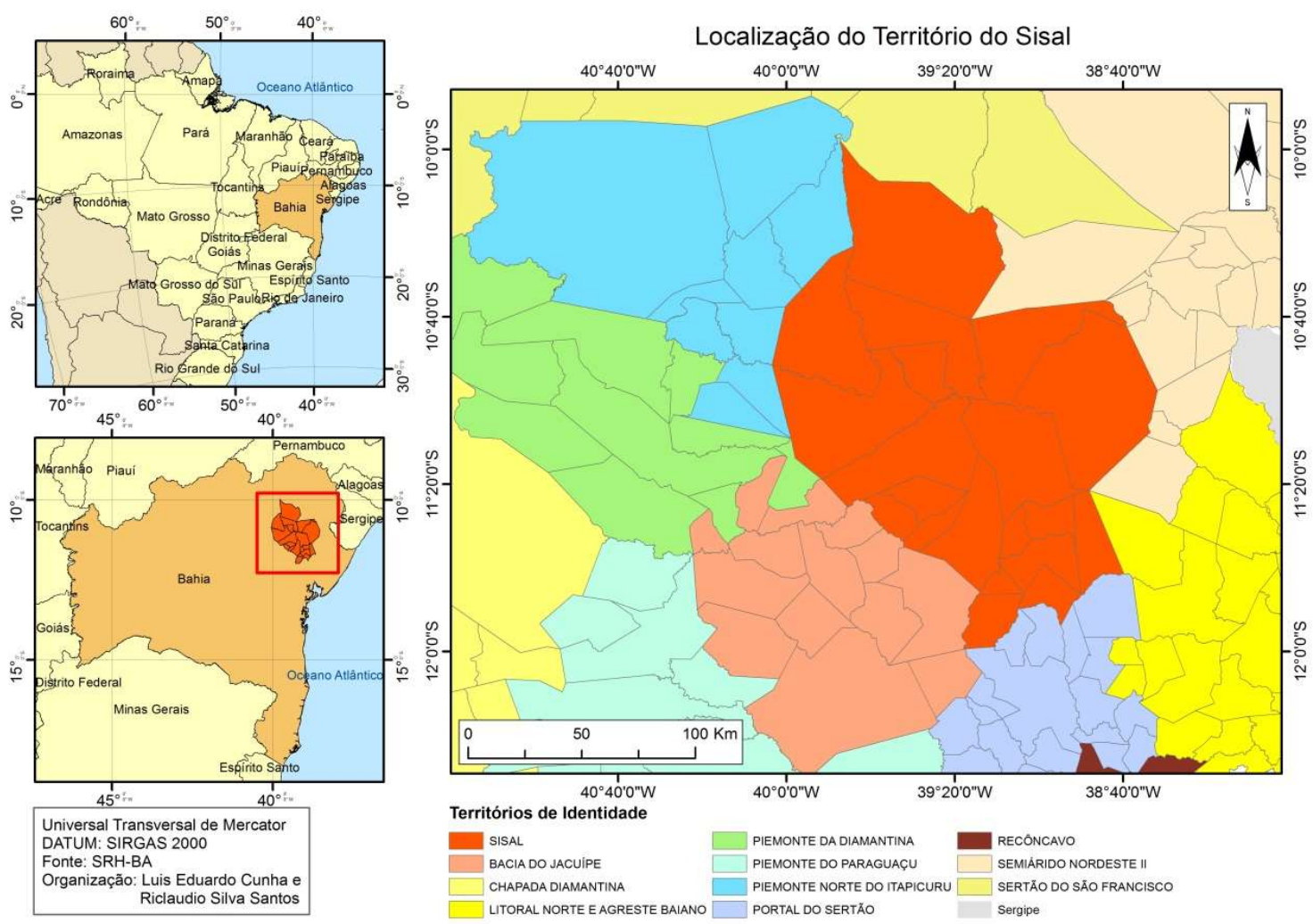

Fonte: Superintendência de Recursos Hídricos, 2012.

Elaboração: Autor, 2017.

A política territorial citada anteriormente e delimitada (mapa 1) é um desmembramento dos projetos de organização do desenvolvimento rural que emerge no contexto nacional a partir da década de 1990, em defesa da modernização ampliada das relações produtivas no campo brasileiro ${ }^{1}$.

As primeiras classificações territoriais identificadas no estado da Bahia surgiram no início do século XXI, a partir dos Territórios da Cidadania, oriunda de uma análise do Governo Federal sobre possíveis agrupamentos de municípios com potenciais condições de

\footnotetext{
${ }^{1}$ No resgate histórico das políticas territoriais situamos o governo de Fernando Henrique Cardoso (1995 - 2003) como destaque. Naquele período, para conter a intensa crise agrária que o país atravessava, adotou-se a estratégia do desenvolvimento das políticas territoriais, através da criação do gabinete do Ministro Extraordinário de Política Fundiária, em 1996, que retirou o tema da alçada do Ministério da Agricultura e criou um planejamento para com a produção agrícola no Brasil dentro dos segmentos do Estado. Em consequência, posteriormente, no ano de 1999, foi criado o Ministério do Desenvolvimento Agrário (MDA). Os planejamentos desenvolvidos através do MDA passaram a promover ações de incentivo à produção agrícola e consolidação da agricultura familiar as cadeias produtivas que o país apresenta. Partindo do pressuposto de análise que a dimensão territorial valorizada a partir daquele período foi o território, pode-se afirmar que as relações de produção instituídas pelo Estado integram uma rede de agricultura familiar que passa a inserir cada vez mais as condições de vida camponesa em estruturas determinadas pelos ditames da agricultura de mercado.
} 
desenvolvimento dos programas territoriais, dando origem ao PTC (Programa dos Territórios de Cidadania).

[...] Os Territórios da Cidadania têm como objetivo promover o desenvolvimento econômico e universalizar programas básicos de cidadania por meio de uma estratégia de desenvolvimento territorial sustentável. A participação social e a integração de ações entre Governo Federal, estados e municípios são fundamentais para a construção dessa estratégia (BRASIL, 2009, p.3).

Destarte, as relações de produção e exploração do trabalho presentes no Território de Identidade do Sisal são de fundamental relevância analítica, tendo em vista que o processo de identidade territorial dos municípios que compõem o Território do Sisal foi construído historicamente através da produção de fibra do sisal, legitimada inicialmente pelos Territórios da Cidadania no âmbito federal e, em seguida, a partir do ano de 2006, na esfera estadual da Bahia com a institucionalização dos Territórios de Identidade.

No que se refere ao desenvolvimento da pesquisa, foram analisados conteúdos bibliográficos sobre a produção da fibra no contexto territorial, bem como a realização de visitas em determinadas unidades produtivas. Condição de inserção na realidade do território que nos permite perceber o quão perversa é a relação produtiva do sisal que se mantém desde meados do século XX, e ainda mais complexo, torna-se este processo ao visualizarmos a sua inserção no mercado da indústria internacional.

\section{DESPINDO O CENÁRIO TERRITORIAL}

Institucionalizado nos planos do MDA durante o ano de 2003, ainda como Territórios da Cidadania, o então Território do Sisal tem se consolidado como referência nacional para a política de desenvolvimento territorial (Mapa 2).

$\mathrm{Na}$ perspectiva de avaliação do governo nas esferas federal e estadual, o presente território registra particularidades que envolvem desde os critérios da unidade territorial, em função da cadeia produtiva da fibra do sisal e demais atividades vinculadas ao associativismo e cooperativismo, até mesmo ao destaque dado pelo governo em promovê-lo como modelo de desenvolvimento territorial.

O Território do Sisal tem se singularizado no âmbito das políticas territoriais, em face da inserção e adesão às concepções e diretrizes do PNDSTR do MDA, bem como pelos resultados efetivos que tem alcançado na implantação desta proposta. Essa preeminência decorre do nível de organização e do protagonismo dos atores sociais e pelas condições sociais 
historicamente construídas, apontadas como precursoras do arranjo políticoinstitucional pretendido pela política estatal. A construção da nova institucionalidade no Território do Sisal é produto das transformações mais amplas ocorridas na sociedade brasileira [processo de democratização ativado por partidos políticos e movimentos sociais], e das condições particulares que foram forjadas regionalmente [gestadas pela atuação das pastorais rurais e pelo Movimento de organização Comunitária]. Esse processo é produto da mobilização e atuação de diversos agentes sociais que vêm contribuindo para tessitura deste território (COELHO NETO, 2009, p. 12).

\section{Mapa 2: Municípios que compõem o Território do Sisal, 2018.}

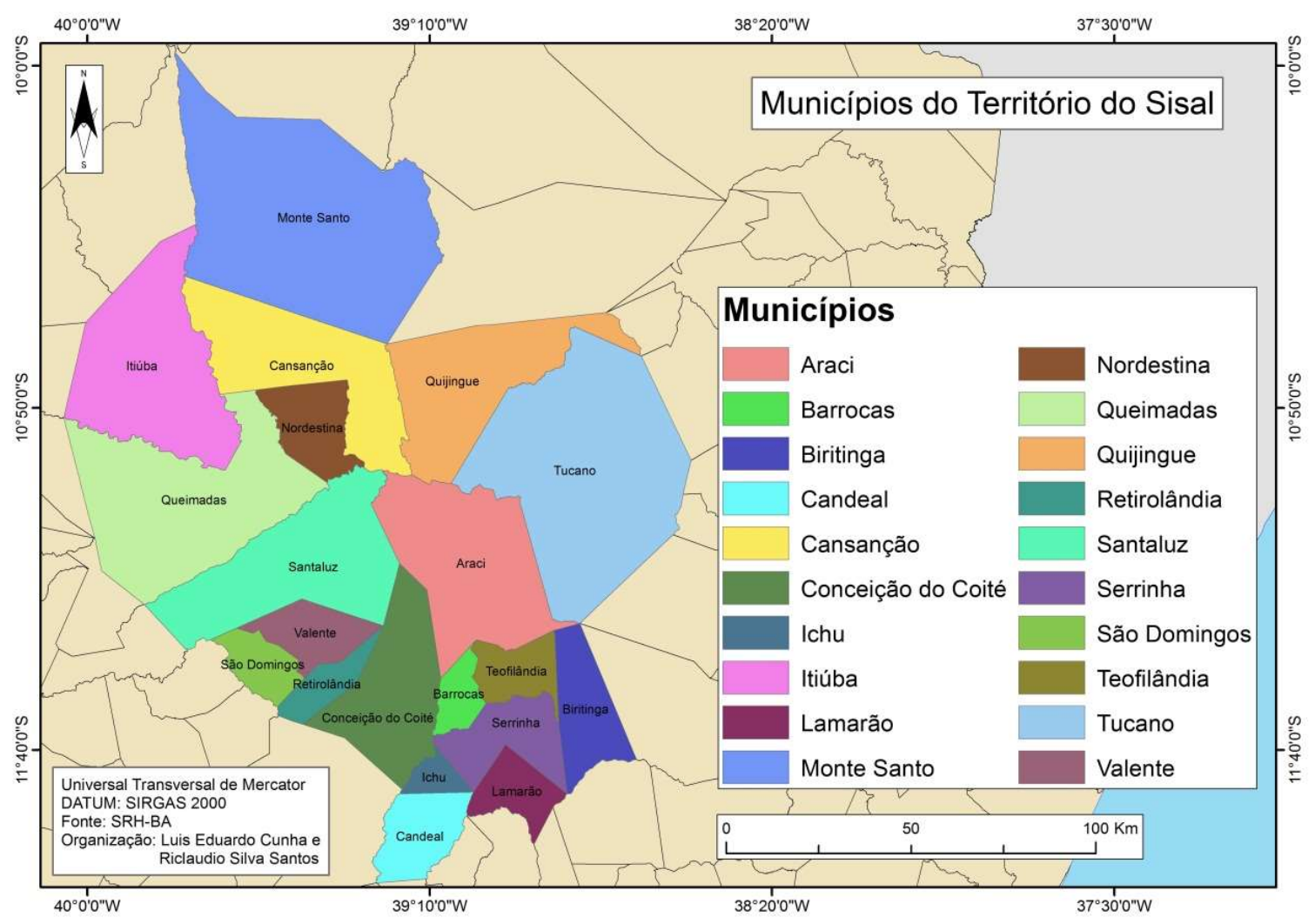

Fonte: Superintendência de Recursos Hídricos, 2012.

Elaboração: Autor, 2017.

Reconhecimento este que também é confirmado pelo próprio MDA/SDT, em nota de publicação oficial sobre as políticas dos “Territórios Rurais" e os programas conveniados nos períodos em que o ministério ainda atuava no território nacional.

O Plano Safra para a agricultura familiar 2004-2005 da Região Nordeste foi lançado em Valente, Bahia, um dos municípios que integram o Território do Sisal, do qual fazem parte dezenove comunidades que estão entre as mais pobres do país, em uma das regiões mais áridas do estado[...] Foram lançadas as novas bases de apoio ao Território do Sisal, uma experiência bem 
sucedida de organização e cooperativismo, que merece a mesma atenção dos demais territórios em fase de estruturação (MDA, 2005, p. 24-25).

Entretanto, para além da narrativa governamental de valorização do Território de Identidade do Sisal na condição de modelo de desenvolvimento Territorial para o país, no que se refere à implantação de políticas territoriais de produção, constata-se um perfil heterogêneo dos municípios que compõem o Território do Sisal em relação à população e ao produto interno bruto, tendo esse último, vínculo direto com a diversidade produtiva do setor terciário nos municípios de maior porte econômico. No entanto, quanto ao índice de desenvolvimento humano médio nota-se uma condição mais similar entre os municípios, sendo inclusive inferior à média nacional registrada pelo PNUD (Plano Nacional de Desenvolvimento Humano - ONU) que é de 0,754 .

Quadro 1. Municípios que integram o Território de Identidade do Sisal.

\begin{tabular}{|c|c|c|c|c|c|c|}
\hline & \multicolumn{3}{|c|}{ População } & & & \\
\hline Município & Total & Urbana & Rural & IDH-M² & $\begin{array}{c}\text { PIB } 2008 \\
\text { Milhões }\end{array}$ & $\begin{array}{c}\text { Índice de } \\
\text { Indigência } \\
(\%)\end{array}$ \\
\hline Araci & 51.651 & 19.638 & 32.013 & 0,557 & 134,50 & 55,07 \\
\hline Barrocas & 14.191 & 5.695 & 8.496 & $\mathrm{~s} / \mathrm{d}$ & 123,31 & $\mathrm{~s} / \mathrm{d}$ \\
\hline Biritinga & 14.836 & 3.517 & 11.319 & 0,596 & 42,22 & 45,38 \\
\hline Candeal & 8.895 & 3.476 & 5.419 & 0,61 & 23,40 & 49,88 \\
\hline Cansanção & 32.908 & 11.021 & 21.887 & 0,538 & 93,01 & 66,49 \\
\hline $\begin{array}{l}\text { Conceição do } \\
\text { Coité }\end{array}$ & 62.040 & 36.278 & 25.762 & 0,611 & 250.32 & 46,57 \\
\hline Ichu & 5.255 & 3.365 & 1.890 & 0,675 & 16,97 & 47,12 \\
\hline Itiúba & 36.113 & 9.699 & 26.414 & 0,574 & 108,82 & 63,27 \\
\hline Lamarão & 9.560 & 2.085 & 7.475 & 0,608 & 25,05 & 43,33 \\
\hline Monte Santo & 52.338 & 8.845 & 43.493 & 0,534 & 135,17 & 69,05 \\
\hline Nordestina & 12.371 & 3.921 & 8.450 & 0,550 & 32,50 & 47,66 \\
\hline Queimadas & 24.602 & 12.492 & 12.110 & 0,613 & 75,76 & 50,94 \\
\hline Quijingue & 27.228 & 6.377 & 20.851 & 0,526 & 106,77 & 69,64 \\
\hline Retirolândia & 12.055 & 6.722 & 5.333 & 0,625 & 45,99 & 61,38 \\
\hline
\end{tabular}




\begin{tabular}{|l|l|l|l|l|l|l|}
\hline Santa Luz & 33.838 & 20.795 & 13.043 & 0,66 & 102,44 & 38,18 \\
\hline São Domingos & 9.226 & 5.916 & 3.310 & 0,624 & 33,22 & 52,70 \\
& & & & & & \\
\hline Serrinha & 76.762 & 47.188 & 29.574 & 0,658 & 319,55 & 44,50 \\
\hline Teofilândia & 21.482 & 6.692 & 14.790 & 0,607 & 54,32 & 55,13 \\
\hline Tucano & 52,418 & 21.958 & 30.460 & 0,582 & 153,77 & 54,34 \\
\hline Valente & 24.560 & 13.487 & 11.073 & 0,657 & 92,75 & 55,13 \\
\hline Total & 582.329 & 249.167 & 333.182 & 0,600 & 98,48 & 50,83 \\
\hline \multicolumn{1}{c}{$\%$} & 100,0 & 42,79 & 57,21 & $/ / / /$ & $/ / / /$ & $/ / / /$ \\
\hline
\end{tabular}

Fonte: $\left({ }^{1}\right)$ IBGE, Censo Demográfico, 2010; $\left({ }^{2}\right)$ Atlas do Desenvolvimento Humano, PNUD, 2010. Elaboração: Autor, 2017.

Em consonância com esses elementos, segundo dados atualizados da Superintendência de Estudos Econômicos e Sociais da Bahia (SEI-BA), o mapeamento estadual dos territórios sobre o nível da população em extrema condição de pobreza classifica o Território do Sisal no grupo dos territórios com maior aprofundamento dessa problemática, apresentando uma concentração em porcentagem no intervalo de 22,71 - 28,40 (Mapa 3), o que não corrobora com a alusão dos discursos governamentais de valorização da política territorial que já foi apresentada no presente texto e que classifica o Território do Sisal como uma das referências nacionais no que tange ao desenvolvimento das políticas territoriais para a transformação da realidade social. 
Mapa 3: Pessoas em extrema pobreza no Estado da Bahia (Por Territórios de Identidade), ano 2013.

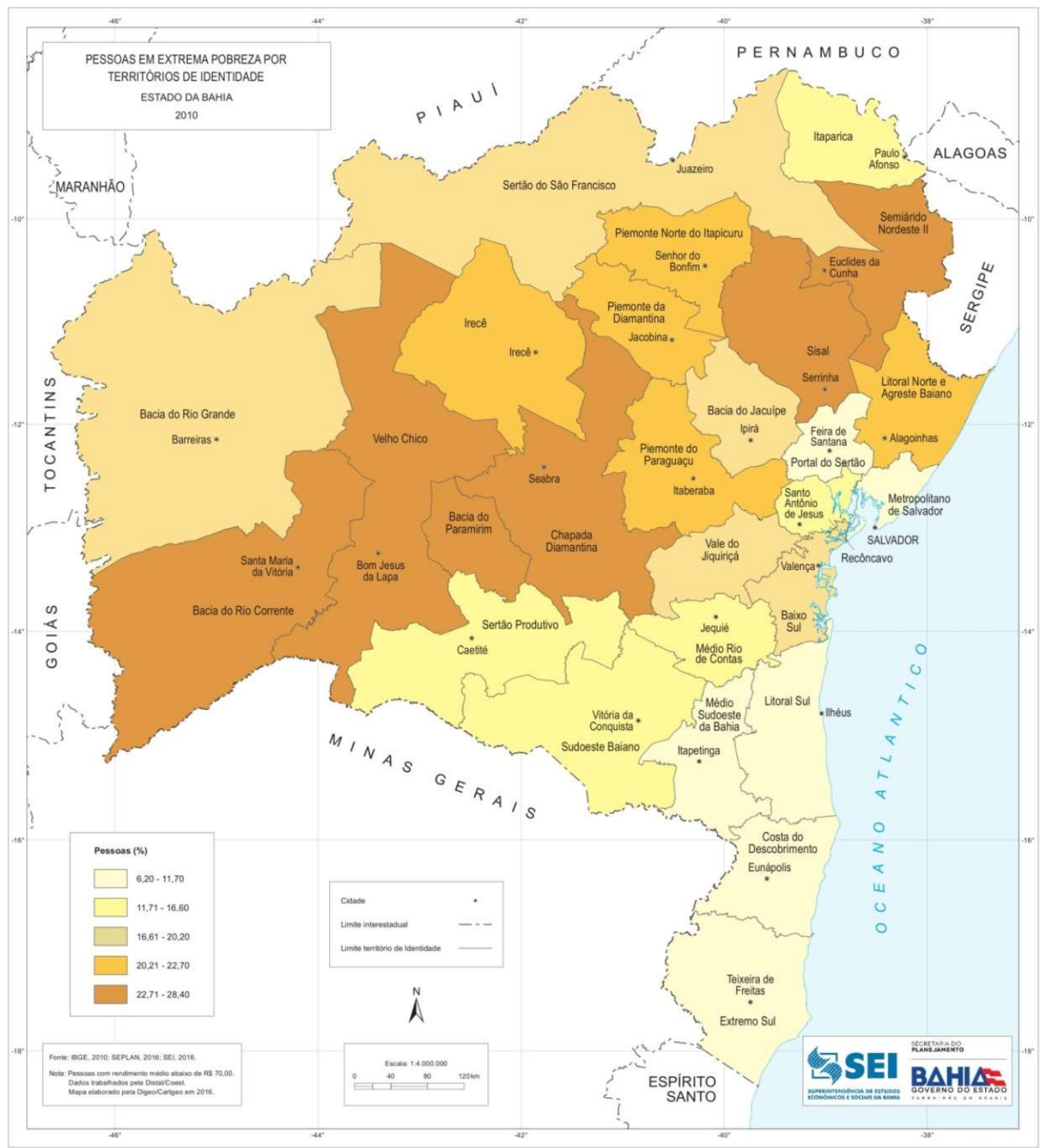

Fonte: Superintendência de Estudos Econômicos e Sociais da Bahia, 2012.

Elaboração: Superintendência de Estudos Econômicos e Sociais da Bahia, 2012.

A condição em que se encontra o Território de Identidade do Sisal no universo de pessoas na extrema pobreza é de se destacar, tendo em vista que mesmo diante de todo o discurso governamental de promoção da política territorial no Território de Identidade do Sisal, a presente unidade territorial apresenta um cenário alarmante de pessoas em miserabilidade econômica. Todavia, esta é a condição de contradição central que fomenta o desenvolvimento da presente pesquisa, por representar a materialidade do contrassenso entre 
o discurso governamental de defesa das políticas territoriais com a real efetividade das mesmas na realidade precária da população mais vulnerável socialmente e em contato com a produção de fibra do sisal.

\section{A CONSTRUÇÃO DA IDENTIDADE TERRITORIAL ATRAVÉS DA EXPLORAÇÃO DO TRABALHO}

Como já foi citado anteriormente, o elemento determinante que constitui a identidade do Território do Sisal e as relações históricas de (re)produção espacial é a produção da fibra do sisal, produção esta que já poderia ser encontrada em alguns municípios que compõem o território desde as primeiras décadas do século XX. A conjuntura atual em torno da cadeia produtiva do sisal é bem menos intensa que os dados iniciais que iremos apresentar, inclusive, alguns municípios que compõem o Território do Sisal não apresentam mais a presença da espécie para o plantio, nem tampouco áreas de cultivo e comercialização da fibra. No entanto, é essa cadeia de produção que dita os processos e agentes da (re)produção espacial no que hoje conhecemos como Território de Identidade do Sisal.

A fibra do sisal é um elemento econômico que representa uma cadeia de produção do semiárido baiano. Proveniente de uma espécie exótica, a fibra é oriunda da agave, espécie originária da península de Yucatán, no México, adaptada muito bem às condições climáticas da região Nordeste do Brasil (Figuras 1 e 2).

A inserção do plantio ocorreu no território brasileiro com maior intensidade nos estados de Alagoas, Bahia, Paraíba, Pernambuco, Rio Grande do Norte, Sergipe e São Paulo. Cabe ressaltar que com exceção deste último, todos os demais apresentavam produção da fibra em extensões do semiárido brasileiro, tornando-se inclusive a única fonte de trabalho e renda para um universo de famílias castigadas pela estiagem prolongada e concentração fundiária. 
Figura 1: Plantio de agave - sisal.

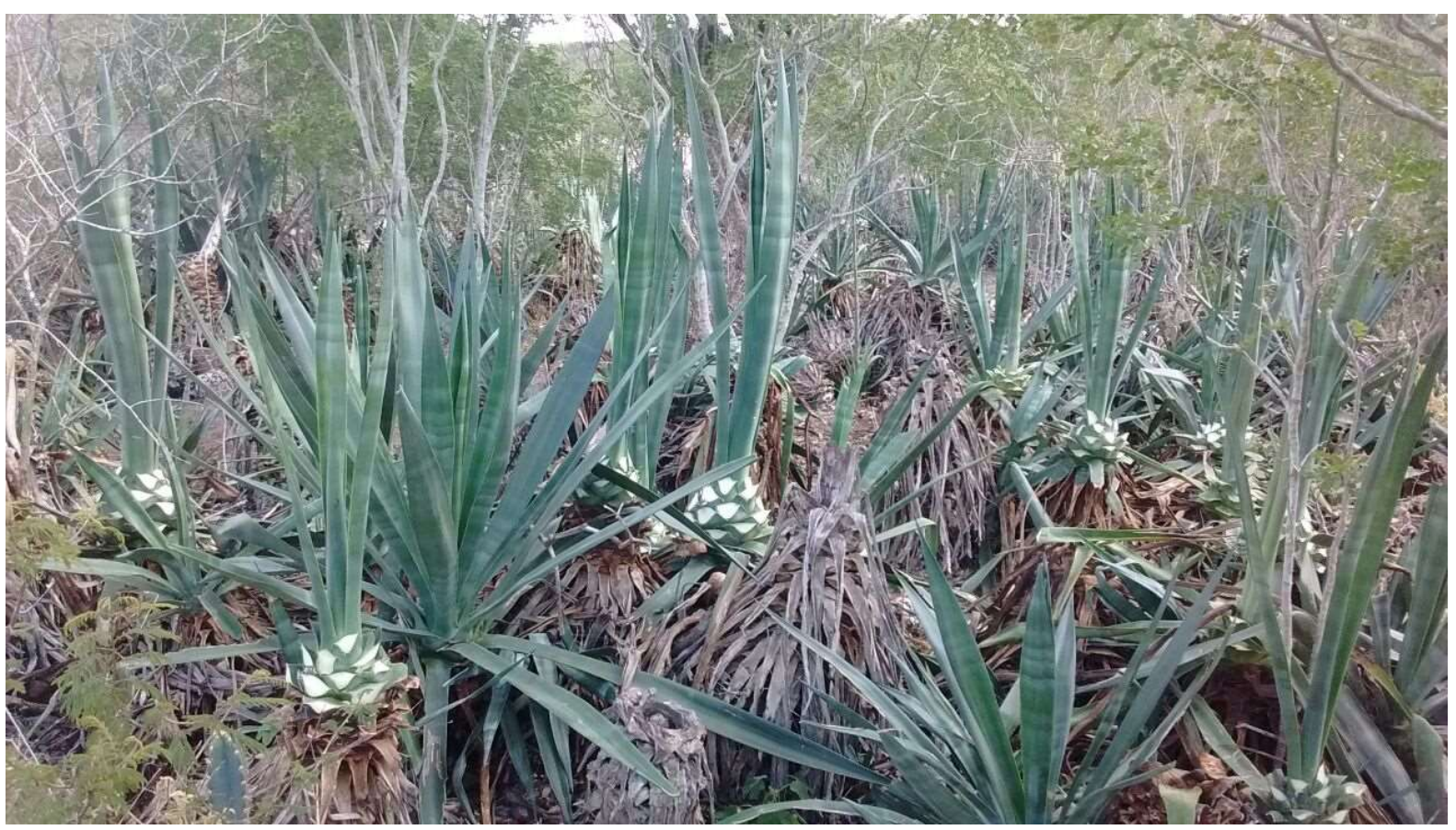

Fonte: Pesquisa de campo, 2017.

Figura 2: Campo de fibra do sisal em processo de secagem.

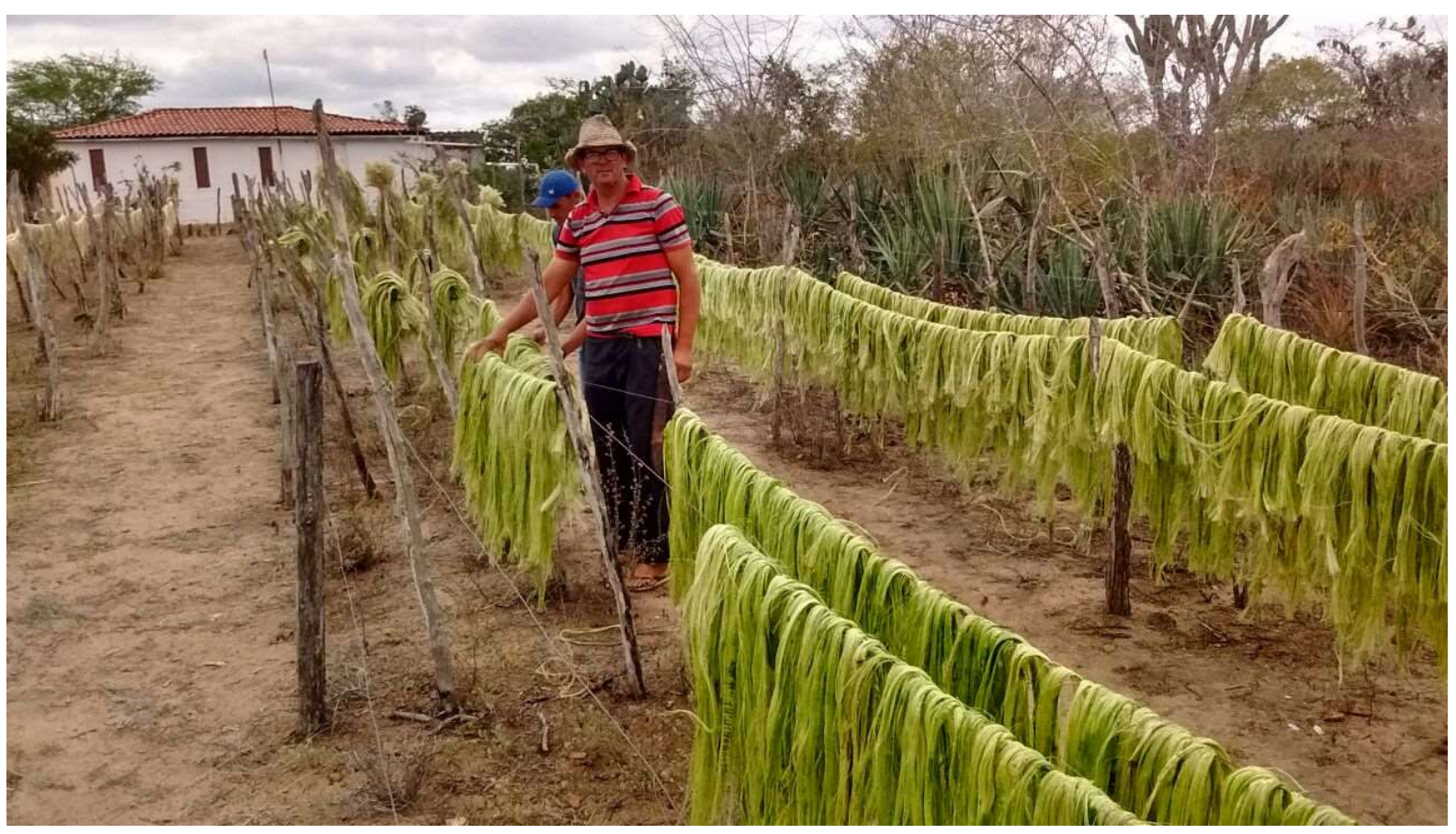

Fonte: Pesquisa de campo, 2017.

Até meados da década de 1930, a espécie era utilizada para a demarcação de propriedades e na pecuária extensiva no intuito de alimentar o rebanho bovino nos períodos de estiagem que assolam o semiárido. 
Durante os períodos que antecederam a II Guerra Mundial, elites locais passaram a iniciar o processo de desfibramento do sisal e introduziram a cadeia produtiva da fibra como conhecemos hoje nas extensões que compreendem o atual Território de Identidade do Sisal. A relação do princípio de produção com o momento pré-guerra que o mundo vivenciava ocorreu em função da necessidade industrial de utilização da fibra para diversos fins bélicos, industriais e civis. A necessidade por fibra no mercado bélico impulsionou a exploração do desfibramento para atender a ampla demanda do mercado internacional. Nesse sentido, o Brasil passou a ampliar a cultura do sisal na região Nordeste o que o colocou entre os grandes produtores mundiais.

Paralelamente há um sensível aumento geral da produção mundial da fibra de agave, para responder a uma procura cada vez mais intensa do mercado mundial. E essa procura corresponde a numerosas utilizações e às necessidades dos países exportadores, necessidades industriais ligadas ao desenvolvimento agrícola, ao progresso marítimo (as cordas para embarcações), cabo submarino e esforço militar (explosivo) (PINTO, 1969, p. 21).

Até 1942, o Brasil estava incluído entre os países importadores da fibra para a indústria. No entanto, a destruição pela guerra dos principais centros produtores da fibra na África e Ásia permitiu a introdução e a expansão rápida da fibra brasileira no mercado mundial. Em 1946 o país já estava presente nas estatísticas de produção mundial, como um dos principais exportadores, com 2.000 toneladas anuais (PINTO, 1969, p.20). No período de 1948-1952, o Brasil ocupava o terceiro lugar na produção mundial das fibras de sisal (Tabela 1). A produção mundial era de 377000 toneladas.

Tabela: 1 - Principais países produtores da fibra do sisal no período de 1948 a 1952.

\begin{tabular}{llc} 
Classificação & País & Produção em toneladas \\
$\mathbf{1}^{\mathbf{0}}$ & Tanganica & 137.000 \\
$\mathbf{2}^{\mathbf{0}}$ & México & 110.000 \\
$\mathbf{3}^{\mathbf{0}}$ & Brasil & 44.000 \\
$\mathbf{4}^{\mathbf{0}}$ & Haiti & 28.000 \\
$\mathbf{5}^{\mathbf{0}}$ & Angola & 21.000 \\
$\mathbf{6}^{\mathbf{0}}$ & Moçambique & 19.000 \\
$\mathbf{7}^{\mathbf{0}}$ & Cuba & 15.000 \\
$\mathbf{8}^{\mathbf{0}}$ & Filipinas & 3.000 \\
Total & & $\mathbf{3 7 7 . 0 0 0}$ \\
\hline
\end{tabular}

Elaboração: Autor, 2017.

Fonte: Pinto, 1969, p.21 
Em 1949, o Brasil exportou 23.018 toneladas de fibra de sisal e a produção provinha, em sua maioria, do estado da Paraíba que detinha uma supremacia na produção. (PINTO, 1969, p.20). O período de transição entre as décadas de 1950-1960 representou um crescimento exponencial no mercado da fibra, tornando o Brasil o segundo maior exportador mundial com $96 \%$ da sua produção destinada à exportação (NASCIMENTO, 2003). No decorrer dos anos de 1950, o estado da Bahia se tornou o segundo maior produtor do Brasil (Tabela 2), ficando com sua produção abaixo do estado da Paraíba, o cenário de produção do país na época era repartido entre os estados da maneira seguinte:

Tabela 2: Principais Estados brasileiros produtores da fibra do Sisal em 1949.

\begin{tabular}{llc} 
Classificação & Estado Brasileiro & Produção em toneladas \\
$\mathbf{1}^{\mathbf{0}}$ & Paraíba & 19.066 \\
$\mathbf{2}^{\mathbf{o}}$ & Bahia & 959 \\
$\mathbf{3}^{\mathbf{o}}$ & Rio Grande do Norte & 655 \\
$\mathbf{4}^{\mathbf{0}}$ & Pernambuco & 138 \\
$\mathbf{5}^{\mathbf{0}}$ & São Paulo & 119 \\
$\mathbf{6}^{\mathbf{0}}$ & Sergipe & 24 \\
Total & & $\mathbf{2 1 . 1 7 7}$ \\
\hline
\end{tabular}

Elaboração: Autor, 2017.

Fonte: PINTO,1969, p.25

Os anos seguintes a esse período expressam um aumento da produção de fibra do sisal no território baiano com rápido crescimento que ocorreu em função dos incentivos para o plantio promovido pelo Estado, e que beneficiava as oligarquias agrárias no intuito de impulsionar o plantio nas áreas pastoris ou de caatinga. Todo esse crescimento do plantio e produção do sisal materializa um processo de regionalização no semiárido baiano, criando a partir do agrupamento de municípios produtores da fibra de sisal que são incluídos na Região Sisaleira da Bahia. Com isso, a cultura do sisal originou uma verdadeira "frente de expansão agrícola" que avançou discretamente pela caatinga pastoril transformando a paisagem local em uma extensão de campos do sisal. Através do impulso promovido pelas administrações municipais e estaduais em função da forte procura da fibra no mercado internacional, o sisal acabou por substituir outras atividades agrícolas (PINTO, 1969, p.39).

Este processo produtivo gerou consequências em diferentes âmbitos sociais, dentre os quais, pode-se situar a constante mobilidade do trabalho. No então período em destaque, diversos trabalhadores oriundos de outros estados começaram a migrar para os municípios produtores de fibra do semiárido baiano. 
Os dados dos recenseamentos de 1940 e 1960 mostram um considerável aumento da população na área estudada. Nesse período, o número de habitantes passou de 382.013 a 579.830 . Assim a densidade que era em 1940 , de $7,50 \mathrm{hab} / \mathrm{km}^{2}$, indicando uma fraca ocupação do solo em região de pecuária, passou a $11,54 \mathrm{hab} / \mathrm{km}^{2}$, em 1960 , ou seja, um aumento $51,78 \%$ superior à média do estado que de $7,15 \mathrm{hab} / \mathrm{km}^{2}$ passou a $10,70 \mathrm{hab} / \mathrm{km}^{2}$. Esse crescimento demográfico da região foi devido, não só ao crescimento natural, como também à imigração proveniente de outros estados do Nordeste, apesar de ocorrer uma saída da população nordestina para os centros urbanos do sul e sudeste do Brasil. (PINTO, 1969, p.48).

Os líderes políticos daquele período e os produtores do sisal sabiam que a Bahia poderia superar a produção paraibana, em função da dimensão territorial do estado que poderia ser transformado em áreas de plantio do sisal. Tendo o pleno conhecimento desse potencial territorial, em 1940 o governo do estado da Bahia planejou o plantio de 12 milhões de mudas do sisal, sendo plantadas apenas 2 milhões. O governo importou a primeira máquina desfibriladora de fabricação estadunidense, com capacidade de produzir $3.000 \mathrm{~kg}$ de fibras em 10 horas de trabalho (MARQUES, 1978, p.19).

A partir desse período, a produção baiana apresentou um largo crescimento produtivo, o que consolidou o estado como maior produtor nacional da fibra de sisal, ampliando assim a acumulação de riqueza em determinados grupos oligárquicos que controlavam a produção e comercialização da fỉbra.

Contemporaneamente a esse processo de expansão da cultura sisaleira ocorreu uma série de processos que visavam à emancipação municipal de povoados e comunidades que hoje se constituem como municípios do Território do Sisal, ou seja, as principais lideranças do período de expansão da cultura do sisal tiveram uma ligação determinante na emancipação de diversos municípios do Território. Com isso, elas passaram a dominar a gestão política dessas unidades municipais.

Destarte

A cultura da agave sisalana teve rápido desenvolvimento na Bahia. Uma das consequências dessa expansão foi o aparecimento de várias localidades e o desenvolvimento de outras. É preciso constatar a criação de novos municípios que têm a fibra do sisal como uma fonte de renda. É o caso de Araci, criado em 1956, de Valente e Cansanção em 1958 e Retirolândia em 1962 (PINTO, 1969, p.17).

Todo esse processo de emancipação política e aumento de poder das elites locais fortaleceram a configuração de monopolização da produção do sisal, tendo em vista que na atualidade o valor de mercado da fibra de sisal está diretamente relacionado com as relações 
de câmbio das moedas internacionais. Nesse sentido, a especulação do valor da fibra de sisal age como um ditame do mercado financeiro, determinando a condição de trabalho dos indivíduos envolvidos na produção, ou seja, quando o valor está em alta, os donos de campo de plantio e demais comerciantes do sisal promovem o processamento da fibra e a intensa exploração do trabalho, mas, quando o valor da fibra entra em declínio no mercado internacional, os trabalhadores se veem numa escassez da oferta de emprego nas comunidades produtoras.

O sisal está na dependência dos preços do mercado internacional, que ditam, então, o curso da Bolsa para a comercialização nacional. A ação da especulação dos mercados internacionais junta-se uma outra, a das grandes firmas exportadoras colocadas em vários países produtores da fibra de sisal (caso da Continental S. A., no Brasil, de capitais portugueses) que fazem o monopólio desse produto (PINTO, 1969, p.21).

Segundo Almeida (2006, p.137), "o sisal aparece nos distintos discursos oficiais e não oficiais, como uma saída para as populações rurais pobres [...]”. A alta do preço do sisal no mercado internacional fez com que o produto passasse a ser considerado o "ouro verde" do sertão nordestino. Nesse sentido, o preparo da fibra do sisal para o mercado internacional criou novas estruturas que evidenciam um desenvolvimento da urbanização e aberturas de comunicação e transporte que facilitam as relações humanas (PINTO, 1969, p.57).

Mas na verdade, o que se observa nessa promoção do cultivo da fibra do sisal é a manutenção do discurso ideológico burguês, disseminado para a manutenção da sociedade de classes, negligenciando inclusive a sua responsabilidade no processo de geração da miséria entre os trabalhadores. E à medida em que a produção da fibra do sisal se consolida no semiárido baiano, a dependência da renda dos trabalhadores em torno da cultura é ainda mais concretizada.

Nesse sentido, enquanto os representantes das elites locais estão à frente dos processos de comercialização do produto com o mercado de exportação e ainda ocupam os espaços políticos-administrativos em determinados municípios, aos trabalhadores resta à venda da sua força de trabalho em condições extremas de precarização e constantes riscos de mutilação do corpo, em função do perigo que o maquinário reproduzido nas unidades de produção das fibras oferece $^{2}$ (Figura 3 ).

\footnotetext{
${ }^{2}$ Apelidada de máquina paraibana, foi inserida na produção regional da fibra de sisal após a expansão da cultura na década de 1950. Em função do baixo custo de compra e manutenção, o maquinário se expandiu com rapidez na produção. No entanto, sendo este um produto de montagem artesanal, o mesmo não oferece segurança aos trabalhadores e produz um exército de indivíduos mutilados pelas localidades produtivas do sisal.
} 
Figura 3: Camponês na atividade de desfibramento do Sisal.

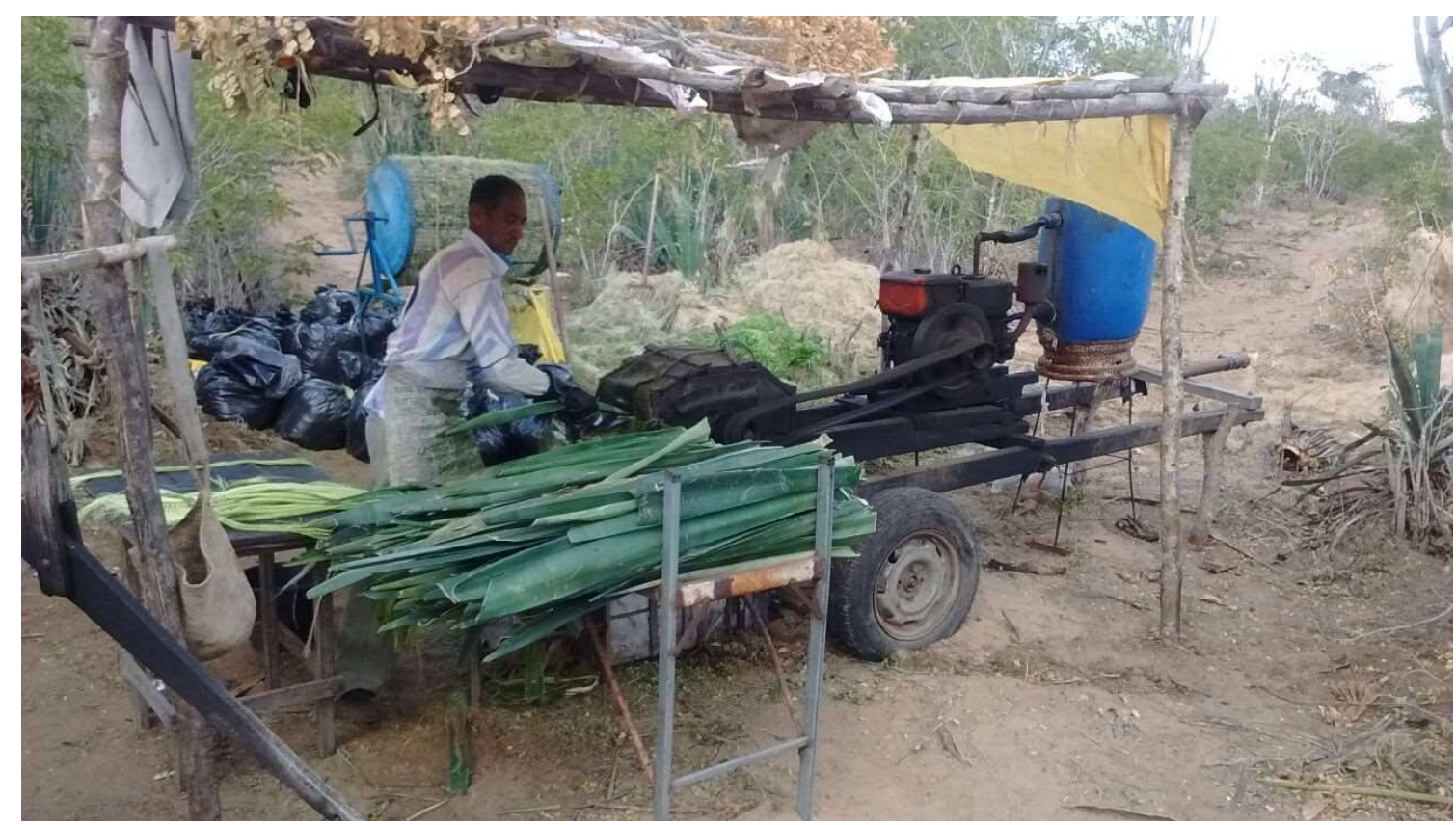

Fonte: Pesquisa de campo, 2017.

A condição de manutenção da precariedade na produção de fibra do sisal já é algo corriqueiro nos campos de cultivo. As primeiras críticas ao modelo de produção surgiram nos primeiros contatos de pesquisadores ao estudarem as atividades nos campos de desfibramento já nos anos iniciais de produção das fibras do sisal.

\begin{abstract}
A assistência social não atingiu ainda o trabalhador do sisal, ele não tem nenhuma garantia; ganha por tarefa e se fica doente não recebe nenhum pagamento. Para o maquinista a situação é ainda pior: apesar da obrigação de fazer seguro de acidente para os motores, os proprietários não o fazem. Em caso de acidente, se o motor é segurado o trabalhador recebe uma indenização, se não ele nada recebe; e o maquinista perde sua mão e, algumas vezes parte do braço. Os exemplos de homens mutilados por acidente pelo motor ou pela batedeira são numerosos. Existem casos em que ao mutilado não resta outra solução que apelar para a caridade (PINTO, 1969, p.54).
\end{abstract}

Cabe ainda ressaltar, a situação destes trabalhadores inseridos na produção da fibra e dependentes da renda que a exploração da sua força de trabalho potencializa na cadeia de produção. Em sua grande maioria, os trabalhadores não apresentam o devido conhecimento dos fins que a fibra contempla após o processamento nos campos de desfibramento. Situação essa que pôde ser diagnosticada por meio de questionários e entrevistas realizadas em um universo de vinte e três trabalhadores rurais nas propriedades privadas, produtoras da fibra de sisal no munícipio de Valente- BA, conforme pode ser visualizado no gráfico 1. 
Gráfico 1: A estrutura de mercado da fibra do sisal na concepção dos camponeses.

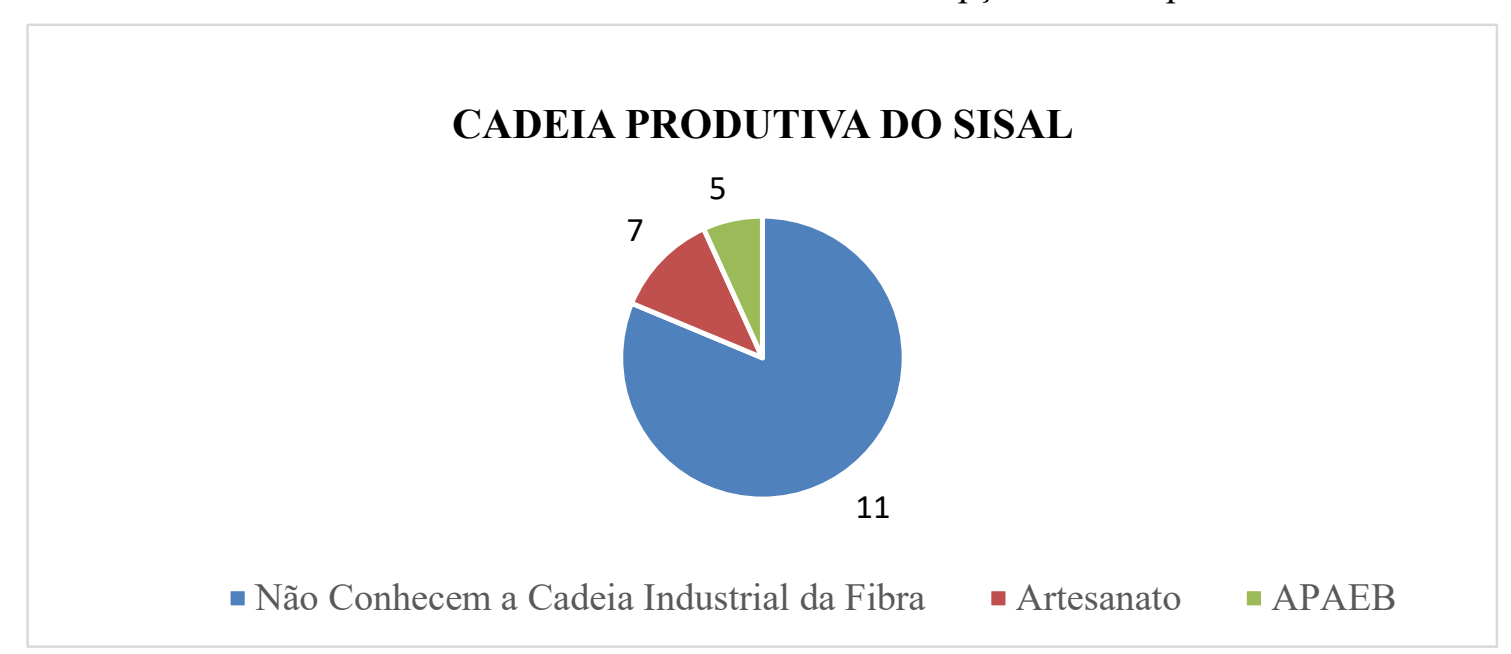

Fonte: Pesquisa de campo, 2017.

Elaboração: Autor, 2017.

Conforme os dados coletados em campo e representados no gráfico 1, onze dos vinte e três trabalhadores entrevistados afirmaram não conhecer a cadeia de produção da fibra do sisal e nem os produtos finais que são confeccionados a partir da matéria prima com a qual trabalham. Isso expressa, a alienação do trabalho na medida em que "o objeto que o trabalho produz, o seu produto, se lhe defronta como um ser estranho, como um poder independente do produtor" (MARX, 2008, p. 80).

A leitura que se pode revelar a respeito é que os trabalhadores apresentam uma situação complexa de dependência da atividade sisaleira, bem como, das condições precárias instauradas pela própria produção, possuindo assim uma função limitadora do crescimento de salário real e garantias trabalhistas asseguradas por lei. O capitalismo conforma um modo de socialização cruel e produz uma morbidez, construindo uma forma social adequada a sua própria reprodução contraditória e desigual (LISBOA, 2007, p. 224).

Em pesquisa de campo, o entrevistado 01 relata a seguinte situação:

Sou natural do município de Valente-BA, sempre trabalhei como lavrador e predominantemente relacionado às atividades do sisal, os únicos períodos que a minha família abandonou a lavoura do sisal era durante os períodos de estiagem prolongada. A condição do trabalho sempre foi pesada e a atividade na máquina (desfibramento) sucessivamente era realizada pelo meu pai, por conta da maior experiência que ele tem com o equipamento que pode causar mutilações. Mas o maior problema do sisal na atualidade é a redução das lavouras. De alguns anos para cá, a produção vem caindo muito, chegamos ao ponto em que os compradores e atravessadores donos de batedeiras estão 
sempre à procura do produto, mas com preços não tão agradáveis. (Entrevista com trabalhador rural. Setembro de 2017).

O período que o entrevistado cita de declínio na produção da fibra do sisal condiz com as oscilações de produção apresentadas pela $\mathrm{CONAB}^{3}$ (Gráfico 2), em função da concorrência dos produtos sintéticos nas indústrias de bens de produção e consumo.

Gráfico 2: Produção da fibra do sisal em toneladas no Brasil.

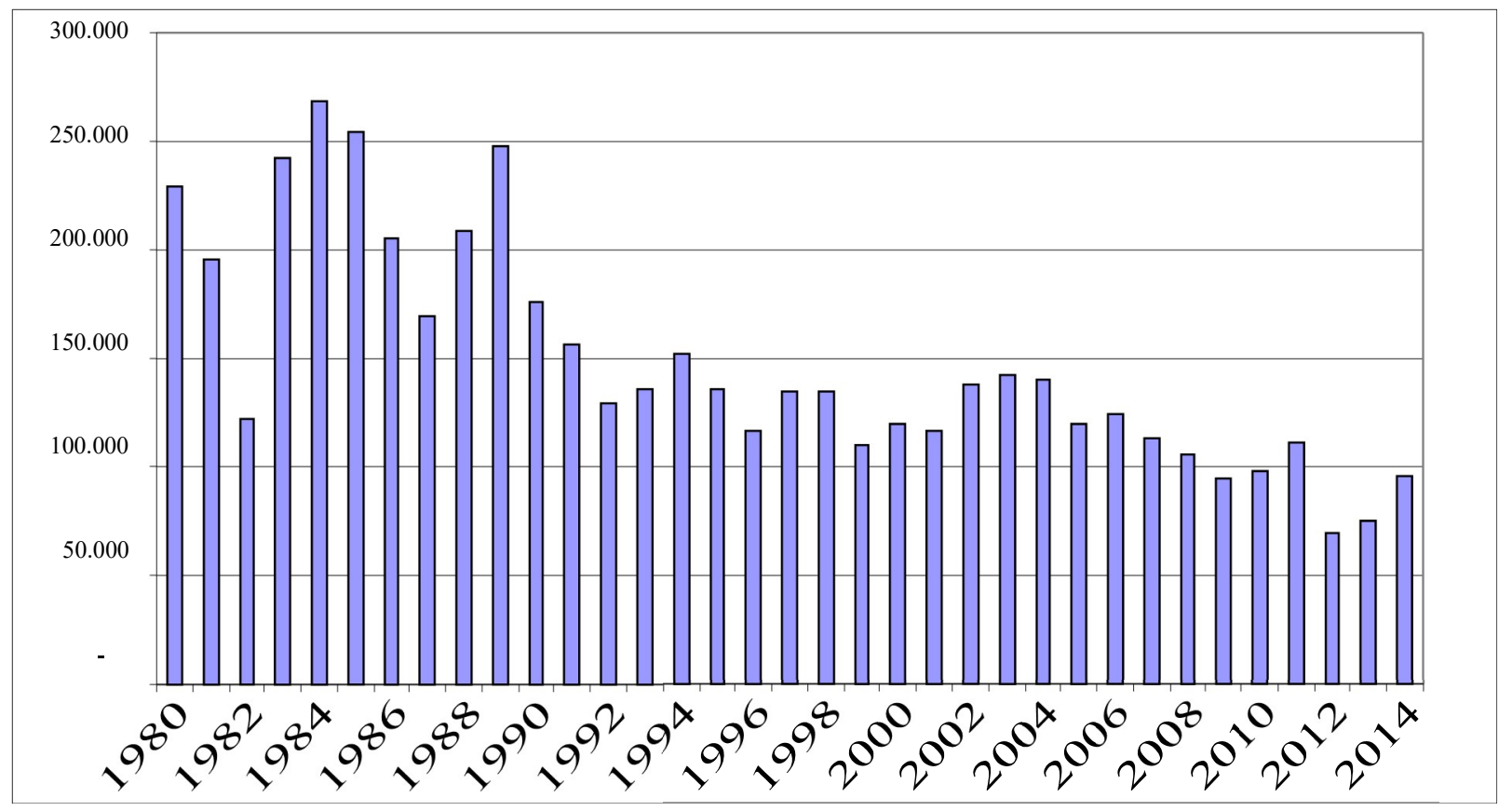

Fonte: Sistema de Informação Conab, 2015.

Elaboração: Conab, 2015.

O principal motivo das mudanças no mercado da fibra é a ascensão dos derivados sintéticos do petróleo que apesentam um preço mais baixo no mercado internacional. No entanto, determinadas finalidades da fibra de sisal não podem ser substituídas pelos sintéticos, a exemplo do uso da fibra nas atividades agrícolas e artesanais. Diante dessa necessidade alguns mercados consumidores mantêm o consumo do produto brasileiro em operação, a exemplo do mercado chinês (Gráfico 3).

A fibra beneficiada de sisal brasileira é exportada para 32 países. A China tradicionalmente o maior comprador dessa fibra, com participação de $51 \%$ em 2015 e $64 \%$ em 2014, todavia, o volume negociado, em 2015, com esse país, foi de 17,4 mil t, 49\% inferior ao transacionado em 2014 (26 mil), como pode ser observado no Gráfico 2. Aludida queda está associada à redução da taxa de crescimento da economia daquele país asiático, refletida na queda da taxa acima de $10 \%$ para a casa dos $6 \%$ em 2016 (CONAB, 2016).

${ }^{3}$ Companhia Nacional de Abastecimento. 
Gráfico 3: Exportações de fibra beneficiada para a China

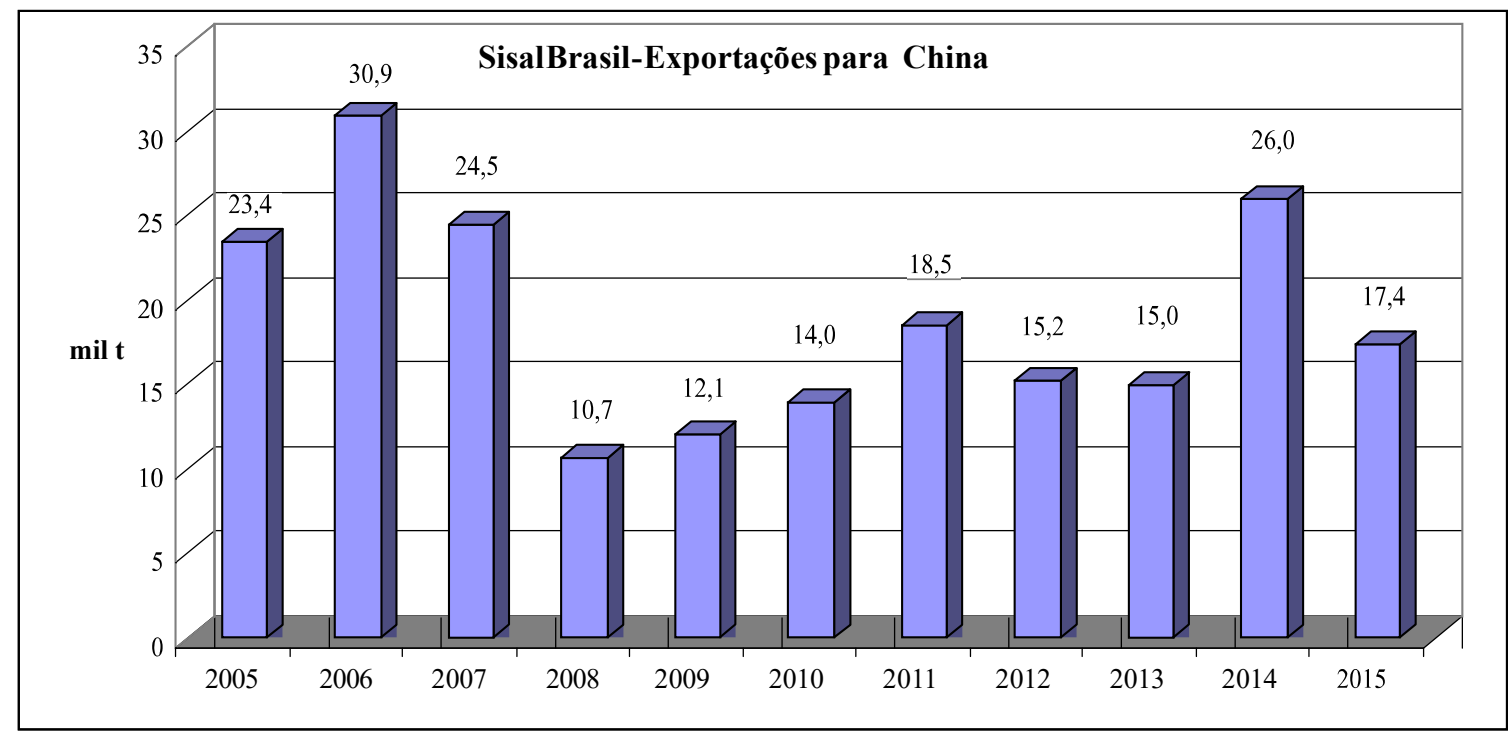

Fonte: Sistema de Informação Conab,2015.

Elaboração: Conab, 2015.

Do ponto de vista da análise da cadeia produtiva do sisal são esses mercados consumidores contínuos que garantem a manutenção da produção da fibra nos municípios produtores do semiárido baiano. Relações de produção e compra que expõem uma cadeia de produção em extrema articulação com o mercado financeiro internacional, mas que apresentam em sua base produtiva condições precárias de trabalho. Em meio a todo esse universo de contradições, a Política de Desenvolvimento Territorial que instituiu o Território de Identidade do Sisal desconsidera essas relações de trabalho e, apesar de dar nome ao território, não desencadeia as ações de transformação dessa realidade.

\section{CONCLUSÃO}

As primeiras inquietações sobre o desenvolvimento do presente estudo objetivaram compreender o atual Território de Identidade do Sisal em meio ao cenário de pobreza permanente em determinadas comunidades visitadas. A produção de fibra do sisal, sempre presente na paisagem semiárida dos municípios cursados, se tornou o elemento de identidade para uma população territorial, além de ser a principal fonte de renda viável para as famílias que desenvolvem o desfibramento.

Todavia, o aprofundamento da cultura de plantio do sisal revela um processo de 
subordinação das relações de trabalho extremamente consolidado e perverso. A dependência da geração de renda familiar vinculada, em prioridade à fibra de sisal, é preocupante no tocante a inexistência de garantias trabalhistas para os trabalhadores e constantes riscos que a produção oferece.

Mediante esses aspectos o que poderia se esperar da política territorial era um significativo enfrentamento a essas situações sociais, através de um maior agrupamento de ações que pudessem estabelecer alternativas mais emancipatórias aos trabalhadores, por meio de outras cadeias produtivas, ou com melhorias no próprio desfibramento do sisal. No entanto, as ações de desenvolvimento territorial apresentam dificuldades em alterar a lógica de exploração do trabalho tão presente nas unidades produtoras da fibra nos espaços que foram visitados. O que torna ainda mais questionável são os reais processos de emancipação humana presentes no Território de Identidade do Sisal, a partir das análises dos documentos da política territorial que visam valorizar as ações desenvolvidas no presente território durante as duas últimas décadas.

Para o tamanho enfrentamento que a transformação da realidade exige dos segmentos estatais e sociais inseridos na realidade territorial, é necessário um efetivo reconhecimento da problemática que as condições de produção da fibra apresentam. A partir disto é possível planejar estratégias em caráter participativo territorial que instituam melhorias cada vez mais necessárias para uma população tão marcada pela exploração constante do trabalho.

\section{REFERÊNCIAS}

ALMEIDA, S.S.M. Memória e Trabalho no Sertão: A peleja dos pequenos agricultores no sisal. Cadernos do SEP ADM, Salvador, n.3, 2006, p.135-147.

BRASIL. Ministério do Desenvolvimento Agrário. Chamada CNPq/MDA/SPM-PR N. 11/20014. Secretaria de Políticas para as Mulheres, Ministério do Desenvolvimento Agrário. Distrito Federal, Brasília, 2014.

BRASIL. Ministério do Desenvolvimento Agrário - MDA. Conselho Nacional de Desenvolvimento Rural Sustentável. Diretrizes para o Desenvolvimento Rural Sustentável. MDA/CONDRAF, 2015.

BRASIL. Ministério do Desenvolvimento Agrário. Referências para a gestão social de territórios rurais. Documento Institucional n. 3. Brasília: Secretaria de Desenvolvimento Territorial - SDT. nov. 2005.

BRASIL. Ministério do Desenvolvimento Agrário. Secretaria de Desenvolvimento 
Territorial. 'Gestão de Território Rurais" - CNPq/MDA/SDT, nº 05/2008. Relatório Analítico. Território de Cidadania do Sisal - Bahia. Feira de Santana, 2011c.

BRASIL. Territórios da Cidadania: integração de políticas públicas para reduzir desigualdades. Brasília, mar. de 2009. Disponível em http://www.terrtoriosdacidadania.gov.br/dotlrn/territriosrurais/pageflip/. Acesso em: $12 \mathrm{dez}$. 2017.

COELHO NETO, A. S. Emergência e atuação das redes de coletivos sociais organizados no Território do Sisal In: (Geo) grafias dos movimentos sociais. Feira de Santana: UEFS Editora, 2009, v.1, p. 305-368.

CONAB. Série Histórica de Produção e Custos do Sisal. Brasília, DF, out. 2017. Disponível em https://www.conab.gov.br/info-agro/custos-de-producao/planilhas-de-custo-deproducao/item/1982-serie-historica-custos-sisal-ba-2011-2017.Acesso em: 17 jul. 2019.

GAlvão, A. C. F. Política Nacional de Desenvolvimento Regional. Resenha. Boletim Regional. Brasília: Ministério da Integração Nacional, n 2, p. 45-48, 2008.

GALVÃO, A. C. F. Por que apoiar políticas de desenvolvimento regional? Ideais sobre alguns dilemas atuais do desenvolvimento. In. BRANDÃO, C.; SIQUEIRA, H. Pacto federativo, integração nacional e desenvolvimento regional. São Paulo: Editora Fundação Perseu Abramo, 2010.

LISBOA, Josefa Bispo de. A trajetória do desenvolvimento para o Nordeste: políticas públicas na (dis)simulação da esperança. 2007. 270 f. Tese (Doutorado em Geografia) Programa de Pós Graduação em Geografia, Universidade Federal de Sergipe, São Cristóvão, 2007.

MARQUES, N. O sisal na Bahia. V Convenção Regional do Sisal. Salvador, 1978.

MARX, K. O capital: Livro III. Rio de Janeiro: Civilização Brasileira, 2008. v.5.

NASCIMENTO, H. M. Conviver o Sertão: Origem e Evolução do Capital Social em Valente. São Paulo: Annablume/ FAPESP, Valente, APAEB, 2003.

PINTO, Maria N. Contribuição ao estudo da influência da lavoura especulativa do sisal no estado da Bahia. Revista Brasileira de Geografia, Rio de Janeiro, n. 31 (3), p. 3-102, jul./set. 1969.

SANTOS, Marleide, Maria. Movimentos sociais: na trama subliminar do ocultamento dos conflitos de classe. 2008. 311f. Tese (Doutorado em Geografia) - Programa de Pós Graduação em Geografia, Universidade Federal de Sergipe, São Cristóvão, SE, 2008. 